\title{
Conformational analysis of 2,2-difluoroethylamine hydrochloride: double gauche effect
}

\author{
Josué M. Silla ${ }^{1}$, Claudimar J. Duarte ${ }^{2}$, Rodrigo A. Cormanich ${ }^{2}$, \\ Roberto Rittner ${ }^{2}$ and Matheus P. Freitas ${ }^{* 1, \S}$
} Open Access

\author{
Full Research Paper \\ Address: \\ ${ }^{1}$ Department of Chemistry, Federal University of Lavras, P. O. Box \\ 3037, 37200-000, Lavras, MG, Brazil and ${ }^{2}$ Chemistry Institute, State \\ University of Campinas, P. O. Box 6154, 13084-971, Campinas, SP, \\ Brazil

\section{Email:} \\ Matheus P. Freitas* - matheus@dqi.ufla.br \\ * Corresponding author \\ § Tel.: +55 35 3829-1891; Fax: +55 35 3829-1271 \\ Keywords: \\ conformational analysis; 2,2-difluoroethylamine hydrochloride; gauche \\ effect; hydrogen bonding
}

\author{
Beilstein J. Org. Chem. 2014, 10, 877-882. \\ doi:10.3762/bjoc. 10.84 \\ Received: 30 December 2013 \\ Accepted: 23 March 2014 \\ Published: 16 April 2014 \\ Associate Editor: J. A. Murphy \\ (c) 2014 Silla et al; licensee Beilstein-Institut. \\ License and terms: see end of document.
}

\begin{abstract}
The gauche effect in fluorinated alkylammonium salts is well known and attributed either to an intramolecular hydrogen bond or to an electrostatic attraction between the positively charged nitrogen and the vicinal electronegative fluorine atom. This work reports the effect of adding a fluorine atom in 2-fluoroethylamine hydrochloride on the conformational isomerism of the resulting 2,2-difluoroethylamine chloride (2). The analysis was carried out using NMR coupling constants in $\mathrm{D}_{2} \mathrm{O}$ solution, in order to mimic the equilibrium conditions in a physiological medium, in the gas phase and in implicit water through theoretical calculations. Despite the presence of $\sigma_{\mathrm{CH}} \rightarrow \sigma^{*}{ }_{\mathrm{CF}}$ and $\sigma_{\mathrm{CH}} \rightarrow \sigma^{*} \mathrm{CN}$ interactions, which usually rule the hyperconjugative gauche effect in 1,2-disubstituted ethanes, the most important forces leading to the double gauche effect $\left({ }^{+} \mathrm{NH}_{3}\right.$ in the gauche relationship with both fluorine atoms) in $\mathbf{2}$ are the Lewis-type ones. Particularly, electrostatic interactions are operative even in water solution, where they should be significantly attenuated, whereas hyperconjugation and hydrogen bond have secondary importance.
\end{abstract}

\section{Introduction}

The conformational isomerism of alkylamines devotes interest because intramolecular effects relative to hydrocarbon analogues are affected by the electronegativity of the nitrogen atom and by the basicity of the amino group. However, most drug like molecules based on this class of compounds are proto- nated to give ammonium salts. In some cases, there is a strong conformational shift toward the gauche orientation between nitrogen and the electronegative substituent (such as the fluorine atom) after protonation of the nitrogen atom in a 2-substituted ethylamine fragment [1-5]. According to theoretical calcu- 
lations, such conformational preference takes place in the gas phase and persists in water solution, where most biochemical processes occur.

We have recently shown that, in water solution, the axial preference of 3-fluoropiperidinium hydrochloride ( $\mathrm{F}$ and $\mathrm{N}$ with gauche arrangement) is dependent on hyperconjugation, and not only due to $\mathrm{F} \cdots \mathrm{HN}^{+}$hydrogen bond and/or electrostatic attraction between the electronegative fluorine with the positively charged nitrogen [6]. However, introduction of an additional 2-fluorine atom in that fragment to give 2,2-difluoroethylammonium salts generates incremental interactions and, thus, the contributions from Lewis and non-Lewis-type interactions should differ from those found in singly fluorinated ethylammonium salts.

The Lewis-type interactions result from four-electron/twoorbital interactions, such as steric effects and dipolar (electrostatic) interactions. On the other hand, non-Lewis-type interactions refer to electron delocalization from filled to empty orbitals, such as hyperconjugation. Indeed, the $\sigma_{\mathrm{CH}} \rightarrow \sigma^{*} \mathrm{CF}$ hyperconjugative interaction has been found to be the main factor controlling the gauche effect in 1,2-difluoroethane and derivatives [7-9]. Nevertheless, the electrostatic gauche effect has been found to be operative in some $\beta$-fluoro- $N$-ethylpyridinium cations of interest, as well as in the $\mathrm{C} 2$ '-endo conformation of $\mathrm{NAD}^{+}[5]$.

Since multifluorination represents a relevant challenge in organic synthesis and in the development of polar organic compounds with attractive properties [10] and because alkylammonium salts are present in a variety of pharmaceuticals, the present work focuses on describing the conformational isomerism in 2,2-difluoroethylamine hydrochloride.

\section{Results and Discussion}

The conformational isomerism of 2,2-difluoroethylamine (1) was computationally investigated at the MP2/6-311++g(d,p) level, both in the gas phase and implicit water (using the Polarizable Continuum Model). The conformational preferences are consistent with those obtained elsewhere through theoretical calculations and infrared spectroscopy [11]. No significant double gauche effect has been found in $\mathbf{1}$, since conformers possessing two fluorine atoms in the gauche relationship with the amino group (gauche-gauche, gg) are estimated to be similarly populated to those conformers with only one single fluorine gauche to the nitrogen atom (anti-gauche, ag) (Table 1). In fact, the most stable conformer of the neutral compound contains two fluorines gauche to the amino group, which presents both hydrogens directed toward fluorines, suggesting the formation of F $\cdots \mathrm{HN}$ hydrogen bond. However, the second most stable form ag is calculated to be almost similar in energy with the global minimum, indicating that other intramolecular effects take place and/or that the above mentioned hydrogen bond makes a small contribution towards the stabilization of the global minimum. Second-order perturbation analysis of donoracceptor interactions in the natural bond orbitals (NBOs) framework shows that the global minimum of $\mathbf{1}$ is more stabilized by hyperconjugation than the other conformers (both in the gas phase and implicit water), despite being significantly destabilized by Lewis-type interactions.

The conformational preference dramatically changes after protonation of $\mathbf{1}$ to give the 2,2-difluoroethylammonium cation

\begin{tabular}{|c|c|c|c|c|c|}
\hline Parameter & ag1 & ag2 & ag3 & $g g 1$ & $g g 2$ \\
\hline$E_{\text {rel (gas) }}$ & $0.2(35 \%)$ & - & $0.7(15 \%)$ & $2.4(1 \%)$ & $0.0(49 \%)$ \\
\hline$E_{\text {Lewis (gas) }}$ & 0.2 & - & 7.7 & 5.3 & 7.3 \\
\hline$E_{\text {hyperc (gas) }}$ & 0.0 & - & -7.0 & -2.9 & -7.3 \\
\hline$E_{\text {rel (water) }}$ & $0.4(20 \%)$ & $1.3(4 \%)$ & $0.3(23 \%)$ & $1.0(14 \%)$ & $0.0(39 \%)$ \\
\hline$E_{\text {Lewis (water) }}$ & 3.6 & 1.3 & 7.4 & 3.6 & 8.6 \\
\hline$E_{\text {hyperc (water) }}$ & -3.2 & 0.0 & -7.1 & -2.6 & -8.6 \\
\hline
\end{tabular}


(2), i.e. the conformer containing both fluorines gauche to the ammonium group $(g g)$ is practically the single form in the equilibrium in the gas phase and, even in water solution, this conformer is calculated to amount to $90 \%$. This preference is corroborated by NMR experiments (Supporting Information, File 1), because the measured ${ }^{3} J_{\mathrm{H}, \mathrm{H}}$ and ${ }^{3} J_{\mathrm{H}, \mathrm{F}}$ coupling constants (which have angular dependence according to the well known Karplus curve [12-14]) are consistent with the average values calculated for the $g g$ conformer (Table 2). The experimental coupling constants for $\mathbf{2}$ in $\mathrm{D}_{2} \mathrm{O}$ solution are ${ }^{3} J_{\mathrm{H}, \mathrm{H}}=2.6 \mathrm{~Hz}$ and ${ }^{3} J_{\mathrm{H}, \mathrm{F}}=16.4 \mathrm{~Hz}$, and the mean calculated values for the $g g$ conformer in implicit water are $1.3 \mathrm{~Hz}$ and $16.8 \mathrm{~Hz}[(2.8+30.7) / 2=16.8]$, while the corresponding values for the ag conformer are $5.5 \mathrm{~Hz}$ and $12.4 \mathrm{~Hz}$.

Table 2: Calculated parameters ( $E$ in kcal $\mathrm{mol}^{-1}$ and $J$ in $\mathrm{Hz}$ ) obtained for $\mathbf{2}$ in the gas phase and implicit water (conformer populations are given in parenthesis).

\begin{tabular}{|c|c|c|}
\hline Parameter & ag & $g g$ \\
\hline$E_{\text {rel (gas) }}$ & $4.2(0 \%)$ & $0.0(100 \%)$ \\
\hline$E_{\text {Lewis (gas) }}$ & 12.4 & 0.0 \\
\hline$E_{\text {hyperc (gas) }}$ & -8.2 & 0.0 \\
\hline$\sigma_{\mathrm{CH}} \rightarrow \sigma^{*} \mathrm{CF}$ (gas) & 2.7 & $3.0 / 3.0$ \\
\hline$\sigma_{\mathrm{CH}} \rightarrow \sigma^{*} \mathrm{CN}$ (gas) & & 3.2 \\
\hline$\sigma_{\mathrm{CH}} \rightarrow \sigma^{*} \mathrm{CH}$ (gas) & $2.0 / 1.7$ & \\
\hline$\sigma_{\mathrm{CF}} \rightarrow \sigma^{*} \mathrm{CH}$ (gas) & 0.8 & $0.9 / 0.9$ \\
\hline$\sigma_{\mathrm{CN}} \rightarrow \sigma^{*} \mathrm{CH}$ (gas) & & 0.9 \\
\hline$\sigma_{\mathrm{CF}} \rightarrow \sigma^{*} \mathrm{CN}$ (gas) & 1.4 & \\
\hline$\sigma_{\mathrm{CN}} \rightarrow \sigma^{*} \mathrm{CF}$ (gas) & 1.1 & \\
\hline${ }^{3} J_{\mathrm{H}, \mathrm{H}}$ (gas) & $3.0 / 8.3$ & $1.0 / 1.0$ \\
\hline${ }^{3} J_{H, F}$ (gas) & $-1.9 / 5.3 / 9.4 / 23.9$ & $2.3 / 2.3 / 24.0 / 24.0$ \\
\hline$E_{\text {rel (water) }}$ & $1.3(10 \%)$ & $0.0(90 \%)$ \\
\hline$E_{\text {Lewis (water) }}$ & 1.8 & 0.0 \\
\hline$E_{\text {hyperc (water) }}$ & -0.5 & 0.0 \\
\hline$\sigma_{\mathrm{CH}} \rightarrow \sigma^{*} \mathrm{CF}$ (water) & 3.5 & $3.7 / 3.7$ \\
\hline$\sigma_{\mathrm{CH}} \rightarrow \sigma^{*} \mathrm{CN}$ (water) & & 3.4 \\
\hline$\sigma_{\mathrm{CH}} \rightarrow \sigma^{*} \mathrm{CH}$ (water) & $2.2 / 1.9$ & \\
\hline$\sigma_{\mathrm{CF}} \rightarrow \sigma^{*} \mathrm{CH}$ (water) & 0.8 & $0.8 / 0.8$ \\
\hline$\sigma_{\mathrm{CN}} \rightarrow \sigma^{*} \mathrm{CH}$ (water) & & 0.8 \\
\hline$\sigma_{\mathrm{CF}} \rightarrow \sigma^{*} \mathrm{CN}$ (water) & 1.5 & \\
\hline$\sigma_{\mathrm{CN}} \rightarrow \sigma^{*} \mathrm{CF}$ (water) & 1.3 & \\
\hline${ }^{3} J_{\mathrm{H}, \mathrm{H}}$ (water) & $2.2 / 8.8$ & $1.3 / 1.3$ \\
\hline${ }^{3} J_{\mathrm{H}, \mathrm{F}}$ (water) & $-0.7 / 7.4 / 10.4 / 32.3$ & $2.8 / 2.8 / 30.7 / 30.7$ \\
\hline
\end{tabular}

The positive charge on nitrogen attracts the fluorine atoms, while the $\mathrm{F} \cdots \mathrm{HN}^{+}$hydrogen bond is not expected to be signifi- cantly affected if compared to $\mathbf{1}$. In fact, QTAIM analysis does not capture any bond path between $\mathrm{F}$ and $\mathrm{H}\left(\mathrm{N}^{+}\right)$to indicate a hydrogen bond. Likewise, the 'quantum' nature of this hydrogen bond (the $n_{\mathrm{F}} \rightarrow \sigma^{*} \mathrm{NH}$ interaction) is not detected by NBO analysis. However, the new non-covalent interaction (NCI) approach, which is based on the electron density and its derivatives, enables the identification of non-covalent interactions by means of peaks that appear in the reduced density gradient (RDG) at low densities [15-17]. Indeed, the NCI method was capable of identifying $\mathrm{F}^{\cdots} \cdot \mathrm{HN}^{+}$hydrogen bond in $\mathbf{2}$ both in the gas phase and implicit water (Figure 1). For both $\mathbf{1}$ and 2, NCI isosurfaces corresponding to $\mathrm{F} \cdots \mathrm{HN}^{+}$hydrogen bonds are larger in the gas phase than in water solution and also the RDG values are closer to zero (Figure 1) for the first than the latter, indicating that such interactions are stronger in the gas phase than in water. The RDG peaks located in the negative valued $\operatorname{sign}\left(\lambda_{2}\right) \rho$ graph area, which correspond to hydrogen bonds and refer to blue NCI isosurfaces in Figure 1, are 0.154 and 0.217 for the $a g$ and $g g$ geometries in the gas phase, respectively, while the corresponding values in water are higher $(0.322$ and $0.331)$. Also, the more negative -0.015 au and -0.013 au $\operatorname{sign}\left(\lambda_{2}\right) \rho$ values for $a g$ and $g g$ in the gas phase in comparison with these conformers in water -0.010 au and -0.009 au, respectively, indicate that $\mathrm{F}^{\cdots} \mathrm{HN}^{+}$hydrogen bonds are stronger in the gas phase than in water from the NCI point of view. Since two interactions of this type are present in $g g$ against only one in $a g$, the $g g$ conformer is expected to be more stabilized by hydrogen bonds than ag conformer, even though the $\mathrm{F} \cdots \mathrm{HN}^{+}$ hydrogen bonds in $g g$ are weaker than in $a g$ as indicated by the aforementioned RDG and $\operatorname{sign}\left(\lambda_{2}\right) \rho$ values.

Once $\mathrm{F}^{\cdots} \mathrm{HN}^{+}$hydrogen bonds are also expected to operate in $\mathbf{1}$, the high energy difference between conformers in $\mathbf{2}$ relative to $\mathbf{1}$ should have another origin. Decomposition of the full energy in the conformers of $\mathbf{2}$ into Lewis and non-Lewis-type interactions, using the NBO method $\left(E=E_{\mathrm{L}}+E_{\mathrm{NL}}\right)$, shows that the $a g$ conformer is more stabilized by hyperconjugation than $g g$ in the gas phase (by $8.2 \mathrm{kcal} \mathrm{mol}^{-1}$ ), despite the large prevalence of the $g g$ conformer (by $4.2 \mathrm{kcal} \mathrm{mol}^{-1}$ ) (Table 2). Such result indicates that $g g$ is significantly favored by Lewis-type interactions, particularly by electrostatic effects (by ca. $12.4 \mathrm{kcal}$ $\mathrm{mol}^{-1}$ ), in agreement with the electrostatic gauche effect. Even in implicit water, where the conformational energy is reduced to $1.3 \mathrm{kcal} \mathrm{mol}^{-1}$ and intramolecular dipolar effects are expected to be attenuated, the contribution from hyperconjugation for both conformers are very similar, while the electrostatic gauche effect favors the $g g$ form by ca. $1.8 \mathrm{kcal} \mathrm{mol}^{-1}$.

Individual antiperiplanar hyperconjugative interactions similar to those responsible for the gauche effect in 1,2-difluoroethane 
ag (gas)

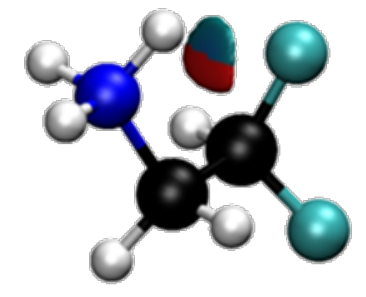

$a g$ (water)

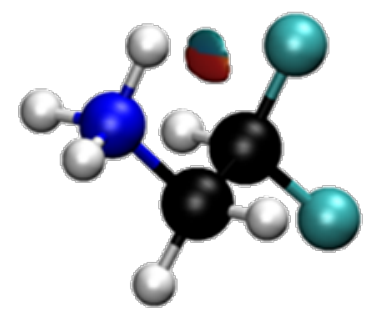

gg (gas)

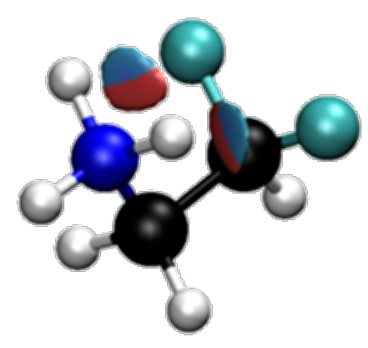

$g g /($ water)

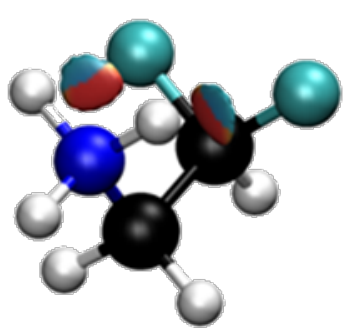

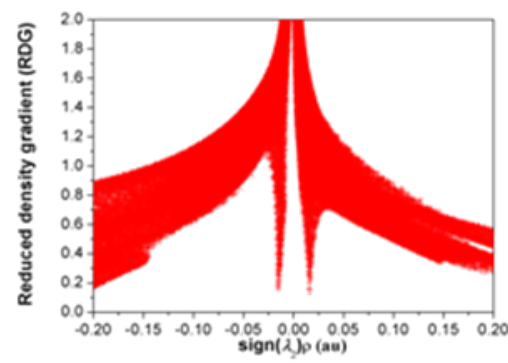
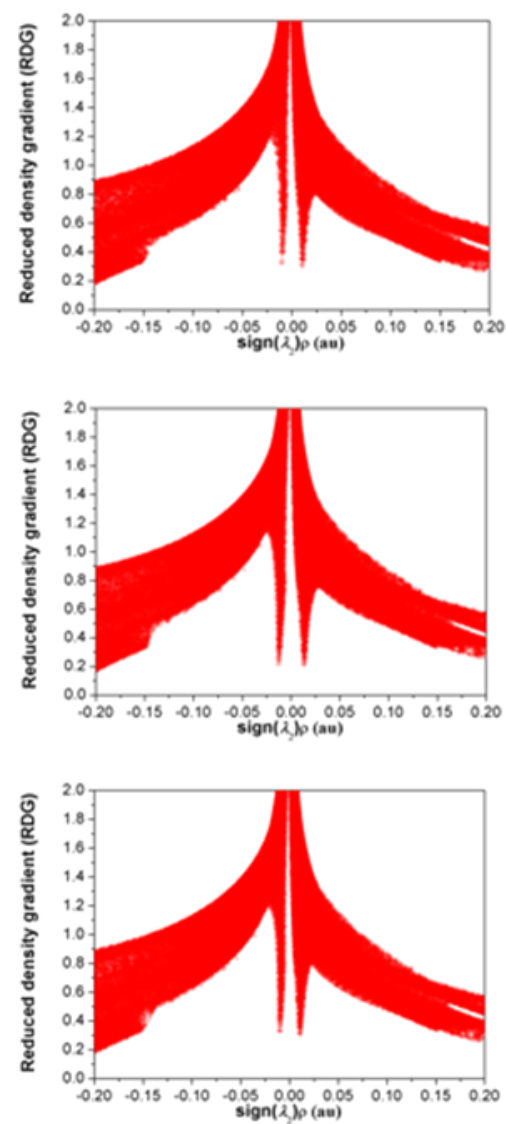

Figure 1: $\mathrm{NCl}$ domains and the plot of reduced density gradient (RDG) vs sign $\left(\lambda_{2}\right) \rho$ for the conformers of 2 . $\mathrm{NCl}$ isosurfaces were obtained with $\mathrm{RDG}=0.5$. The blue-red color scale ranges from $-0.02<\operatorname{sign}\left(\lambda_{2}\right) \rho<+0.02 \mathrm{au}$.

favor the $g g$ conformer in comparison with $a g$, but the sum of all electron delocalizations in $\mathbf{2}$ indicates that $a g$ is more stabilized than $g g$ by hyperconjugative effects (Table 2). Thus, the origin of the double gauche effect in $\mathbf{2}$ is predominantly due to electrostatic attraction between fluorines and the positively charged nitrogen, even in water solution, while hydrogen bond and hyperconjugation interactions play a secondary role for the conformational preference in $\mathbf{2}$. This is different from findings for monofluorinated ethylammonium cations [6], and the results can be useful when evaluating the rules of stereochemical control during the development of multifluorinated alkylammonium cations.

\section{Conclusion}

Both fluorine substituents bonded to a single carbon in an ethane fragment prefer the gauche orientation relative to an ammonium group, either in the gas phase or aqueous solution, giving rise to the so called double gauche effect. The origin of this effect in these media was found to be predominantly electrostatic, due to the attraction between the positively charged nitrogen and the electronegative fluorines, despite the participation of intramolecular hydrogen bond and hyperconjugation. These findings can be useful to predict the structure and stereochemistry of multifluorinated organic compounds with, e.g., pharmaceutical and/or agrochemical interest. 


\section{Experimental}

2,2-Difluoroethylamine hydrochloride (2) was purchased from Sigma-Aldrich and used without further treatment. The ${ }^{1} \mathrm{H}$ NMR experiments were performed on a Bruker AVANCE III spectrometer operating at $499.87 \mathrm{MHz}$ using ca. $20 \mathrm{mg} \mathrm{mL}^{-1}$ in $\mathrm{D}_{2} \mathrm{O}$ solution.

Compounds 1 and 2 present a total of 2 rotatable bonds, and considering the staggered conformations, as well as degenerate structures, five minima for $\mathbf{1}$ and two minima for $\mathbf{2}$ are expected. All geometries were optimized at the MP2/6$311++\mathrm{g}(\mathrm{d}, \mathrm{p})$ level $[18,19]$ in the gas phase and using implicit solvent $\left(\mathrm{H}_{2} \mathrm{O}\right)$ according to the Polarizable Continuum Model (PCM) of Tomasi and coworkers [20]. Natural bond orbital (NBO) [21] analyses were also performed at the B3LYP/6$311++\mathrm{g}(\mathrm{d}, \mathrm{p})$ level of theory $[19,22,23]$, including deletion of all antibonding and Rydberg-type orbitals. Spin-spin coupling constants were calculated at the BHandH/EPR-III level [24,25]. All these calculations were carried out using the Gaussian 09 program [26]. Quantum theory of atoms in molecules (QTAIM) calculations were performed to search for possible hydrogen bonds and their stabilities using the AIMAll program [27]. The non-covalent interaction (NCI) method was carried out by using the NCIPLOT program [28].

\section{Supporting Information}

\section{Supporting Information File 1 \\ ${ }^{1} \mathrm{H}$ NMR spectrum of 2 . \\ [http://www.beilstein-journals.org/bjoc/content/ supplementary/1860-5397-10-84-S1.pdf]}

\section{Acknowledgements}

The authors thank FAPEMIG, FAPESP (Grant \# 2012/03933-5, São Paulo Research Foundation) and CNPq for the financial support of this research, as well as for the scholarships (to J.M.S., C.J.D. \#2011/11098-6 FAPESP and R.A.C. \#2011/ 01170-1 FAPESP) and fellowships (to R.R. and M.P.F.).

\section{References}

1. Lankin, D. C.; Grunewald, G. L.; Romero, F. A.; Oren, I. Y.; Snyder, J. P. Org. Lett. 2002, 4, 3557-3560. doi:10.1021/ol026358c

2. Snyder, J. P.; Chandrakumar, N. S.; Sato, H.; Lankin, D. C. J. Am. Chem. Soc. 2000, 122, 544-545. doi:10.1021/ja9934504

3. Lankin, D. C.; Chandrakumar, N. S.; Rao, S. N.; Spangler, D. P.; Snyder, J. P. J. Am. Chem. Soc. 1993, 115, 3356-3357. doi:10.1021/ja00061a055

4. Sun, A.; Lankin, D. C.; Hardcastle, K.; Snyder, J. P. Chem.-Eur. J. 2005, 11, 1579-1591. doi:10.1002/chem.200400835
5. Gooseman, N. E. J.; O'Hagan, D.; Peach, M. J. G.; Slawin, A. M. Z.; Tozer, D. J.; Young, J. R. Angew. Chem., Int. Ed. 2007, 46, 5904-5908. doi:10.1002/anie.200700714

6. Silla, J. M.; Silva, W. G. D. P.; Cormanich, R. A.; Rittner, R.; Tormena, C. F.; Rittner, R.; Freitas, M. P. J. Phys. Chem. A 2014, 118, 503-507. doi:10.1021/jp410458w

7. Goodman, L.; Gu, H.; Pophristic, V. J. Phys. Chem. A 2005, 109, 1223-1229. doi:10.1021/jp046290d

8. Buissoneaud, D. Y.; van Mourik, T.; O'Hagan, D. Tetrahedron 2010, 66, 2196-2202. doi:10.1016/j.tet.2010.01.049

9. Souza, F. R.; Freitas, M. P.; Rittner, R. J. Mol. Struct.: THEOCHEM 2008, 863, 137-140. doi:10.1016/j.theochem.2008.06.003

10. O'Hagan, D. J. Org. Chem. 2012, 77, 3689-3699. doi:10.1021/jo300044q

11. Durig, J. R.; Klaassen, J. J.; Panikar, S. S.; Darkhalil, I. D.; Ganguly, A.; Guirgis, G. A. J. Mol. Struct. 2011, 993, 73-85. doi:10.1016/j.molstruc.2010.10.028

12. Karplus, M. J. Chem. Phys. 1959, 30, 11-15. doi:10.1063/1.1729860

13. Karplus, M. J. Phys. Chem. 1960, 64, 1793-1798. doi:10.1021/j100841a001

14. Karplus, M. J. Am. Chem. Soc. 1963, 85, 2870-2871. doi:10.1021/ja00901a059

15. Johnson, E. R.; Keinan, S.; Mori-Sánchez, P.; Contreras-García, J.; Cohen, A. J.; Yang, W. J. Am. Chem. Soc. 2010, 132, 6498-6506. doi:10.1021/ja100936w

16. Contreras-García, J.; Yang, W.; Johnson, E. R. J. Phys. Chem. A 2011, 115, 12983-12990. doi:10.1021/jp204278k

17. Lane, J. R.; Contreras-García, J.; Piquemal, J.-P.; Miller, B. J.; Kjaergaard, H. G. J. Chem. Theory Comput. 2013, 9, 3263-3266. doi:10.1021/ct400420r

18. Head-Gordon, M.; Pople, J. A.; Frisch, M. J. Chem. Phys. Lett. 1988, 153, 503-506. doi:10.1016/0009-2614(88)85250-3

19. Krishnan, R.; Binkley, J. S.; Seeger, R.; Pople, J. A. J. Chem. Phys. 1980, 72, 650-654. doi:10.1063/1.438955

20. Tomasi, J.; Mennucci, B.; Cammi, R. Chem. Rev. 2005, 105, 2999-3094. doi:10.1021/cr9904009

21. NBO, 5.0; Theoretical Chemistry Institute, University of Wisconsin: Madison, 2001.

22. Becke, A. D. Phys. Rev. A 1988, 38, 3098-3100. doi:10.1103/PhysRevA.38.3098

23. Lee, C.; Yang, W.; Parr, R. G. Phys. Rev. B 1988, 37, 785-789. doi:10.1103/PhysRevB.37.785

24. Becke, A. D. J. Chem. Phys. 1993, 98, 5648-5652. doi:10.1063/1.464913

25. Barone, V. In Recent Advances in Density Functional Methods, Part I; Chong, D. P., Ed.; World Scientific Publ. Co.: Singapore, 1996.

26. Gaussian 09, Revision A.02; Gaussian, Inc.: Wallingford, CT, USA, 2009.

27. AIMAll, 13.02.26; TK Gristmill Software: Overland Park KS, USA, 2013, http://aim.tkgristmill.com.

28. Contreras-García, J.; Johnson, E. R.; Keinan, S.; Chaudret, R.; Piquemal, J.-P.; Beratan, D. N.; Yang, W. J. Chem. Theory Comput. 2011, 7, 625-632. doi:10.1021/ct100641a 


\section{License and Terms}

This is an Open Access article under the terms of the Creative Commons Attribution License

(http://creativecommons.org/licenses/by/2.0), which permits unrestricted use, distribution, and reproduction in any medium, provided the original work is properly cited.

The license is subject to the Beilstein Journal of Organic Chemistry terms and conditions:

(http://www.beilstein-journals.org/bjoc)

The definitive version of this article is the electronic one which can be found at:

doi:10.3762/bjoc. 10.84 